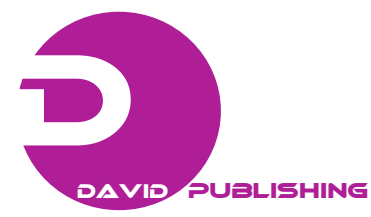

\title{
Characteristics of Superconductivity in
}

\section{Superconductors}

\author{
$\mathrm{Yu} \mathrm{Chen}^{1}$, Jinbin $\mathrm{Yao}^{2}$ and $\mathrm{Li} \mathrm{Yu}{ }^{3}$ \\ 1. School of Chemistry and Environmental Science, Shaanxi University of Technology, Hanzhong 723001, China \\ 2. School of Physics and Telecommunication Engineering, Shaanxi University of Technology, Hanzhong 723001, China \\ 3. School of Foreign Languages, Shaanxi University of Technology, Hanzhong 723001, China
}

Received: May 31, 2014 / Accepted: June 15, 2014 / Published: June 25, 2014.

\begin{abstract}
Superconductivity univerally exists in a wide range of materials like free elements, alloy, oxide, metal salts, organics and so on, and superconductors itself consists of one or two, or even more elements chemical mixture. Therefore, studies on superconductivity characteristics in superconductors in search of its common features are crucial to the exploration of new superconductors and key to the establishement and description of superconductivity theory. Based on a thorogh analysis of superconductivity characteristics in diversified superconductors, the paper concludes that the different superconductivity characteristics in superconductors result from different bond pattern in superconductor elements, but the general superconductivity mechanism of all superconductors remain the same.
\end{abstract}

Key words: superconductivity, superconductivity characteristics, superconductivity mechanism.

\section{Introduction}

In 1911, Kamerling Onnes discovered the loss of resistance in mercury at $4.2 \mathrm{~K}$, or superconductivity [1]. Since then, researches into superconductivity in solid materials have been far and wide, including the studies in free elements, alloy, oxide, metal salts, organics and mixture [2]. The transition temperature of these superconductors may range from above $0.001 \mathrm{~K}$ to more than $134 \mathrm{~K}$ at high pressure [3]. This pheonomena provies the researchers with varied possible projects and challenges on the way to the researches into new materials $[4,5]$. Therefore, it is significant to conduct studies on analyzing the superconductivity characterstics in search of the general regularities in different superconductors. Based on a thorogh analysis of superconductivity characteristics in diversified superconductors, the paper concludes that the different superconductivity

\footnotetext{
Corresponding author: $\mathrm{Yu}$ Chen, professor, research field: high $\mathrm{T}_{\mathrm{c}}$ superconductivity mechanism. E-mail: yuchenshaanxi@126.com.
}

characteristics in superconductors result from different bond pattern in superconductor elements, but the general superconductivity mechanism of all superconductors remain the same.

\section{Method}

There are two basically different types of elements bonding in superconductors, namely metallic bonding and chemical bonding (covalent and ionic).

According to metallic bond features and chemical bond, the superconductors can fall into two categories:

(1) Metallic bond superconductors, in which elements carrying superconductivity are bonded together through metallic bonding;

(2) Chemical bond superconductors, in which elements carrying superconductivity are bonded together through chemical bonding (covalent and ionic).

The all superconductors' superconductivity are produced with electron media phonon mechanism. The different are the Cooper Pairs electrons originating from the different electrons of the elements in 
superconductors. The metallic bond superconductors' Cooper Pairs electrons originate valence electrons of the bearing superconductivity elements in superconductors while the chemical superconductors' Cooper Pairs electrons originate non-bonded electrons of the bearing superconductivity elements in superconductors.

\section{Characteristics}

\subsection{Symmetry of Superconductors Electrons Pairs}

Table 1 lists some superconductors, specifying their respective valence electrons orbits, bond pattern and superconductivity [6].

Table 1 shows that (1) the change of $d$ electron numbers does not affect the symmetry of superconductors electrons pairs; (2) the change of valence electrons layers structures does not affect the symmetry of superconductors electrons pairs; (3) the change of valence electrons orbits follows the pattern of s-ds-fds, leading to the formation of metallic bonding, and the symmetry of superconductors electrons pairs still remains.

This is the case because of the bonding characteristics of metallic bond which is formed when the valence electrons energy is reduced to form conductive electrons in metals. But superconductors electrons pairs start with the conductive electrons, that is, the valence electrons. It can be learned from Table 1 that the orbits characteristics of outmost layer in valence electrons are mainly to determine the symmetry of superconductors electrons pairs. Due to the valence electrons orbits structures of s-ds-fds, the symmetry of superconductors electrons pairs only is determined by the $\mathrm{S}$ orbit characteristics of valence electrons layers, for the outmost layer of sub-electrons is $\mathrm{S}$ orbit in valence electrons orbits structures.

Table 2 lists some superconductivity characteristics in A15 type superconductors [6].

Table 2 shows that (1) bonding pattern of the elements carrying conductivity determines the superconductivity characteristics of A15 type superconductors; (2) the delectrons numbers change in valence electron of the elements carrying conductivity does not affect the symmetry of superconductivity electrons pairs; (3) valence electrons orbits structural change does not affect symmetry of superconductivity electrons pairs; (4) bond pattern in non-bearing superconductivity elements is not related to electron pair symmetry, and the change in valence electrons layer, orbit or the number of valence electrons is unrelated to superconductivity electrons pairs symmetry; (5) similar the result in Table 1, metallic

Table 1 Characteristics of valence electrons orbits, bonding pattern and superconductivity of some superconductors.

\begin{tabular}{|c|c|c|c|c|c|c|}
\hline $\begin{array}{l}\text { Superconducting } \\
\text { material }\end{array}$ & $\begin{array}{l}\text { Valence electrons } \\
\text { orbits structure }\end{array}$ & $\begin{array}{l}\text { Bonding } \\
\text { pattern }\end{array}$ & $\begin{array}{l}\text { Symmetry of superconductivity } \\
\text { electrons pairs }\end{array}$ & $\mathrm{T}_{\mathrm{c}}$ value $(\mathrm{K})$ & $\begin{array}{l}\text { Superconductivity } \\
\text { mechanism }\end{array}$ & $\begin{array}{l}\text { Superconduction } \\
\text { theroy }\end{array}$ \\
\hline $\begin{array}{l}\text { Cs (under } \\
\text { pressure) }\end{array}$ & $6 s^{1}$ & M & ( & 1.6 & e-h & $\mathrm{BCS}$ \\
\hline $\begin{array}{l}\text { Ba (under } \\
\text { pressure) }\end{array}$ & $6 s^{2}$ & M & $\mathrm{S}$ & 1.3 & e-h & $\mathrm{BCS}$ \\
\hline $\mathrm{La}$ & $5 d^{1} 6 s^{2}$ & M & $\mathrm{S}$ & 5.98 & e-h & $\mathrm{BCS}$ \\
\hline Hf & $4 f^{14} 5 d^{2} 5 s^{2}$ & M & S & 0.165 & $e-h$ & BCS \\
\hline $\mathrm{Ta}$ & $4 f^{14} 5 d^{2} 5 s^{2}$ & M & S & 4.48 & $e-h$ & BCS \\
\hline W & $4 f^{14} 5 d^{3} 5 s^{2}$ & M & S & 0.12 & e-h & BCS \\
\hline $\operatorname{Re}$ & $4 f^{14} 5 d^{4} 5 s^{2}$ & M & S & 1.7 & $e-h$ & BCS \\
\hline Os & $4 f^{14} 5 d^{5} 6 s^{2}$ & M & S & 0.65 & $e-h$ & BCS \\
\hline $\mathrm{Ir}$ & $4 f^{14} 5 d^{6} 6 s^{2}$ & M & S & 0.14 & $e-h$ & BCS \\
\hline $\mathrm{Hg}$ & $4 f^{14} 5 d^{10} 6 s^{2}$ & M & S & 4.15 & e-h & BCS \\
\hline V & $3 d^{3} 4 s^{2}$ & M & S & 5.3 & $e-h$ & BCS \\
\hline $\mathrm{Nb}$ & $4 d^{4} 5 s^{1}$ & M & S & 9.26 & $e-h$ & BCS \\
\hline $\mathrm{Pa}$ & $6 d^{4} 7 s^{1}$ & M & S & 1.4 & $e-h$ & BCS \\
\hline
\end{tabular}

Note: M stands for metallic bond, and e-h for electron-phonon mechanism. 
Table 2 characteristics of some A15 superconductors.

\begin{tabular}{lllllll}
\hline Superconductors & $\mathrm{V}_{3} \mathrm{Si}$ & $\mathrm{V}_{3} \mathrm{Ga}$ & $\mathrm{Nb}_{3} \mathrm{Al}$ & $\mathrm{Nb}_{3} \mathrm{Sn}$ & $\mathrm{Nb}_{3}\left(\mathrm{Al}_{0.15} \mathrm{Ge}_{0.25}\right)$ & $\mathrm{Nb}_{3} \mathrm{Ge}$ \\
\hline $\begin{array}{l}\text { valence electrons structure of the bearing superconductivity } \\
\text { elements }\end{array}$ & $3 \mathrm{~d}^{3} 4 \mathrm{~s}^{2}$ & $3 \mathrm{~d}^{3} 4 \mathrm{~s}^{2}$ & $4 \mathrm{~d}^{4} 5 \mathrm{~s}^{1}$ & $4 \mathrm{~d}^{4} 5 \mathrm{~s}^{1}$ & $4 \mathrm{~d}^{4} 5 \mathrm{~s}^{1}$ & $4 \mathrm{~d}^{4} 5 \mathrm{~s}^{1}$ \\
valence electrons structure of the non-bearing superconductivity & $2 \mathrm{~S}^{2} 3 \mathrm{p}^{2}$ & $4 \mathrm{p}^{1}$ & $3 \mathrm{~S}^{2} 3 \mathrm{p}^{1}$ & $5 \mathrm{p}^{2}$ & $3 \mathrm{~S}^{2} 3 \mathrm{p}^{1}, 4 \mathrm{p}^{2}$ & $4 \mathrm{p}^{2}$ \\
elements & $\mathrm{M}$ & $\mathrm{M}$ & $\mathrm{M}$ & $\mathrm{M}$ & $\mathrm{M}$ & $\mathrm{M}$ \\
Element bonding bearing superconductivity elements & $\mathrm{C}$ & $\mathrm{C}$ & $\mathrm{M}$ & $\mathrm{M}$ & $\mathrm{M}, \mathrm{C}$ & $\mathrm{C}$ \\
Element bonding in non- bearing superconductivity elements & $\mathrm{S}$ & $\mathrm{S}$ & $\mathrm{S}$ & $\mathrm{S}$ & $\mathrm{S}$ & $\mathrm{S}$ \\
Symmetry of superconductor electrons pairs & 17.0 & 16.8 & 18.8 & 18.1 & 21.0 & 23.2 \\
$\mathrm{~T}_{\mathrm{c}}(\mathrm{K})$ value & $\mathrm{e}-\mathrm{h}$ & $\mathrm{e}-\mathrm{h}$ & $\mathrm{e}-\mathrm{h}$ & $\mathrm{e}-\mathrm{h}$ & $\mathrm{e}-\mathrm{h}$ & $\mathrm{e}$ \\
Superconductivity mechanism & $\mathrm{BCS}$ & $\mathrm{BCS}$ & $\mathrm{BCS}$ & $\mathrm{BCS}$ & $\mathrm{BCS}$ & $\mathrm{BCS}$ \\
Superconduction theroy & & &
\end{tabular}

Notes: M stands for metallic bond, e-h for electron-phonon mechanism, and $\mathrm{C}$ for Covalent bond.

Table 3 supeconductivity characteristics of some superconductors.

\begin{tabular}{|c|c|c|c|c|}
\hline superconductors & $\begin{array}{l}\text { copper oxide } \\
\text { superconductors [3] }\end{array}$ & $\begin{array}{l}\text { Element Alloy } \\
\text { superconductors [6] }\end{array}$ & Alloy CeRhTn ${ }_{5}[7]$ & $\mathrm{Sr}_{2} \mathrm{RnO}_{4}[8]$ \\
\hline $\mathrm{T}_{\mathrm{c}}(\mathrm{K})$ & $30-134$ & $0.001-23.5$ & 1.2 & 0.93 \\
\hline Bonding features & Ionic bond & Metallic bond & Metallic bond & Ionic bond \\
\hline Wave of superconductors electrons pairs & $\mathrm{d}$ & $\mathrm{s}$ & $\mathrm{p}$ & $\mathrm{p}$ \\
\hline $\begin{array}{l}\text { Orbits of outmost layer in bearing } \\
\text { superconductivity elements }\end{array}$ & $\mathrm{d}$ & $\mathrm{s}$ & $\mathrm{p}$ & $\mathrm{p}$ \\
\hline
\end{tabular}

Table 4 Energy gap characteristics of some superconductors.

\begin{tabular}{llll}
\hline superconductors & Copper oxide superconductors [3] & Element, metal superconductors [6] & Iron superconductors [9,10] \\
\hline $\begin{array}{l}\text { T }(\mathrm{K}) \\
\begin{array}{l}\text { Element Bonding } \\
\text { characteristics }\end{array}\end{array}$ & I0-134 & $0.001-23.5$ & $17-55$ \\
energy gap symmetry & asymmetrical distribution & Metallic bond & Ionic bond \\
\hline
\end{tabular}

bond is formed between the elements carrying conductivity and the electrons pairs symmetry is determined only by the orbits features in S orbits of the valence electron layer in elements carrying superconductivity. This is the case because the outmost layer of sublayer in valence electron carrying superconductivity turns out to be $\mathrm{S}$ orbits.

Table 3 lists some superconductivity characteristics of some superconductors.

Table 3 shows that (1) the electrons orbits of the outmost electrons layer of the elements carrying superconductivity determines the electrons symmetry of superconductors; (2) regardless of the bond pattern between the elements, the sub-electrons orbits of the outmost layer of bonded elements carrying conductivity determines the symmetry of superconductor electrons pairs.

Table 4 lists some energy gap characteristics of some superconductors.

In Table 4, it can be learned that the way how elements bond together in superconductors determines the characteristics of energy gap in the superconductors.

\subsection{Superconductivity Mechanism Characteristics}

Table 5 lists some superconductivity characteristics of chemical bond superconductors.

Table 5 shows that (1) elements bonding pattern in superconductors may change but the superconductivity mechanism remains the same. In other words, in chemical bond (covalent and ionic), superconductivity arises from electron-phonon mechanism; (2) the value of $T_{c}$ in superconductors is not related to superconductivity mechanism. In other words, $\mathrm{T}_{\mathrm{c}}$ may change greatly when elements are built with chemical bond (covalent and ionic), but the superconductivity 
Table 5 superconductivity characteristics of some chemical bond superconductors.

\begin{tabular}{|c|c|c|c|c|}
\hline superconductors & $\mathrm{T}_{\mathrm{c}}(\mathrm{K})$ & Bonding pattern between elements & Superconductivity mechanism & Superconductor theory \\
\hline $\mathrm{MgB}_{2}[11]$ & 39 & $\mathrm{C}, \mathrm{I}$ & $e-h$ & $\mathrm{BCS}$ \\
\hline $\mathrm{M}_{3} \mathrm{C}_{60}[12]$ & 19 & $\mathrm{C}, \mathrm{I}$ & $e-h$ & $\mathrm{BCS}$ \\
\hline $\mathrm{LiTiO}_{4}[6]$ & 13.7 & I & e-h & $\mathrm{BCS}$ \\
\hline $\mathrm{Pb}\left(\mathrm{Mo}_{6} \mathrm{~S}_{8}\right)[6]$ & 14.7 & $\mathrm{C}, \mathrm{I}$ & e-h & $\mathrm{BCS}$ \\
\hline $\mathrm{NbC}[6]$ & 9 & I & e-h & $\mathrm{BCS}$ \\
\hline $\mathrm{NbN}[6]$ & 17 & I & $e-h$ & $\mathrm{BCS}$ \\
\hline $\mathrm{TaC}[7]$ & 10.2 & I & e-h & $\mathrm{BCS}$ \\
\hline $\mathrm{MoC}[8]$ & 14 & I & $e-h$ & $\mathrm{BCS}$ \\
\hline MDT-TSF [10] & 4.5 & $\mathrm{C}, \mathrm{I}$ & e-h & $\mathrm{BCS}$ \\
\hline $\mathrm{BaPb}_{1-x} \mathrm{Bi}_{x} \mathrm{O}_{3}[2]$ & 13 & I & e-h & $\mathrm{BCS}$ \\
\hline
\end{tabular}

$\mathrm{C}$ stands for covalent bond, I for Ionic bond and e-h for electron-phonon mechanism.

Table 6 some superconductors doped with $C_{60}$.

\begin{tabular}{|c|c|c|c|c|c|c|}
\hline Doping elements & Formula & $\begin{array}{l}\text { Element } \\
\text { Bond }\end{array}$ & $\mathrm{T}_{\mathrm{c}}(\mathrm{K})$ & Lattice constant $(\AA)$ & $\begin{array}{l}\text { Superconductivity } \\
\text { mechanism }\end{array}$ & $\begin{array}{l}\text { Superconduction } \\
\text { theory }\end{array}$ \\
\hline \multirow{14}{*}{ Alkali metal } & $\mathrm{K}_{3} \mathrm{C}_{60}$ & $\mathrm{C}, \mathrm{I}$ & 19.3 & 14.240 & e-h & $\mathrm{BCS}$ \\
\hline & $\mathrm{Rb}_{3} \mathrm{C}_{60}$ & $\mathrm{C}, \mathrm{I}$ & 30 & 14.384 & $e-h$ & $\mathrm{BCS}$ \\
\hline & $\mathrm{RbCsC}_{60}$ & $\mathrm{C}, \mathrm{I}$ & 29 & & $e-h$ & $\mathrm{BCS}$ \\
\hline & $\mathrm{Rb}_{2} \mathrm{CsC}_{60}$ & $\mathrm{C}, \mathrm{I}$ & 31.3 & 14.431 & $e-h$ & $\mathrm{BCS}$ \\
\hline & $\mathrm{RbCs}_{2} \mathrm{C}_{60}$ & $\mathrm{C}, \mathrm{I}$ & 33 & 14.555 & e-h & $\mathrm{BCS}$ \\
\hline & $\mathrm{KRb}_{2} \mathrm{C}_{60}$ & $\mathrm{C}, \mathrm{I}$ & 26 & 14.323 & $e-h$ & $\mathrm{BCS}$ \\
\hline & $\mathrm{K}_{2} \mathrm{CsC}_{60}$ & $\mathrm{C}, \mathrm{I}$ & 24 & 14.293 & e-h & $\mathrm{BCS}$ \\
\hline & $\mathrm{K}_{2} \mathrm{RbC}_{60}$ & $\mathrm{C}, \mathrm{I}$ & 23 & 14.243 & $e-h$ & $\mathrm{BCS}$ \\
\hline & $\mathrm{K}_{1.5} \mathrm{Rb}_{1.5} \mathrm{C}_{60}$ & $\mathrm{C}, \mathrm{I}$ & 22 & 14.253 & $e-h$ & $\mathrm{BCS}$ \\
\hline & $\mathrm{Na}_{2} \mathrm{Cs}\left(\mathrm{NH}_{3}\right)_{4} \mathrm{C}_{60}$ & $\mathrm{C}, \mathrm{I}$ & 29.6 & 14.173 & $e-h$ & $\mathrm{BCS}$ \\
\hline & $\mathrm{Na}_{x} \mathrm{~N}_{y} \mathrm{C}_{60}(x=3 \sim 4)$ & $\mathrm{C}, \mathrm{I}$ & 13 & 14.34 & e-h & $\mathrm{BCS}$ \\
\hline & $\mathrm{Na}_{2} \mathrm{CsC}_{60}$ & $\mathrm{C}, \mathrm{I}$ & 12 & 14.134 & $e-h$ & $\mathrm{BCS}$ \\
\hline & $\mathrm{Na}_{2} \mathrm{RbC}_{60}$ & $\mathrm{C}, \mathrm{I}$ & 2.5 & 14.028 & $e-h$ & $\mathrm{BCS}$ \\
\hline & $\mathrm{Li}_{2} \mathrm{CsC}_{60}$ & $\mathrm{C}, \mathrm{I}$ & 12 & 14.120 & $e-h$ & $\mathrm{BCS}$ \\
\hline \multirow{3}{*}{$\begin{array}{l}\text { Alkaline earth } \\
\text { metal }\end{array}$} & $\mathrm{Sr}_{6} \mathrm{C}_{60}$ & $\mathrm{C}, \mathrm{I}$ & 4 & 11.01 & e-h & $\mathrm{BCS}$ \\
\hline & $\mathrm{Ba}_{6} \mathrm{C}_{60}$ & $\mathrm{C}, \mathrm{I}$ & 7 & 11.171 & $e-h$ & $\mathrm{BCS}$ \\
\hline & $\mathrm{Ca}_{6} \mathrm{C}_{60}$ & $\mathrm{C}, \mathrm{I}$ & $8.2 \sim 8.8$ & 11.179 & $e-h$ & $\mathrm{BCS}$ \\
\hline $\begin{array}{l}\text { Alkali metal and } \\
\text { alkali earth }\end{array}$ & $\mathrm{K}_{2.7} \mathrm{Ba}_{0.3} \mathrm{C}_{60}$ & $\mathrm{C}, \mathrm{I}$ & 17 & & e-h & $\mathrm{BCS}$ \\
\hline \multirow{2}{*}{ Rare earth metal } & $\mathrm{Y}_{2.75} \mathrm{C}_{60}$ & $\mathrm{C}, \mathrm{I}$ & 6 & $27.87 \times 27.98 \times 27.873$ & $e-h$ & $\mathrm{BCS}$ \\
\hline & $\mathrm{Sm}_{x} \mathrm{C}_{60}(x<3)$ & $\mathrm{C}, \mathrm{I}$ & 8 & $28.17 \times 28.07 \times 28.27$ & e-h & $\mathrm{BCS}$ \\
\hline
\end{tabular}

$\mathrm{C}$ stands for covalent bond, and I for Ionic bond.

mechanism remains the same [13].

Table 6 lists some uperconductivity characteristics of superconductors with $\mathrm{C}_{60}$ doping.

Table 6 shows that chemical bond (covalent and ionic) is formed in superconductors with the same mechanism and $T_{c}$ value of superconductivity may change. That is, the $T_{c}$ value is unrelated to superconductivity mechanism.

From the analysis in 3.1 and 3.2, we can come to the conclusion that the superconductivity characteristics may be different because of the different bonding pattern of superconductors elements, but the mechanism for all superconductors remains the same $[14,15]$.

\section{Conclusions}

Through an analysis of the superconductivity characteristics of different types of superconcutors, a 
meaningful conclusion is drawn that the mechanism for all superconductors remains the same and the different performance of superconductivity characteristics is resulted from the difference in elements bonds pattern of superconductors.

\section{References}

[1] H.K. Onnes, The resistence of pure mecury at helium temperature, Commun. Phys. Lab. University Leiden (1991) 121b,124c.

[2] L.Y. Zhang, Theory of Superconducting, Science Press, Beijing, 2003, pp. 5-20.

[3] W.C. Zhou, W.Y. Liang. Fundamental research in high $T_{c}$ superconductivity, Shanghai: Science and Technology Press, Shanghai, China, 1999, pp. 20-50.

[4] M. Normen, Have cuprates earned their stripes, Science 303 (2004) 1985-1986.

[5] G.S. Boebinger, An abnormal normal states, Science 323 (2009) 590-591.

[6] W.Y. Guan, H.C. Li, J.H. Cai, H.S. Wu. Superconductivity (Physics Base), Science Press, Beijing, 1981, pp. 8-15.

[7] Y. Kohori, Y. Yamato, Y. Iwamoto, T. Kohara, Appearance of anisotropic non s-wave superconductivity above critical pressure of antiferromegetic $\mathrm{CeRhIn}_{5}$, The European Physical Journal B 18 (2000) 601-604.
[8] R. Arita, S. Onari, K. Kuroki, H. Aoki, Off-site repulsion-induced triplet superconductivity: A possibility for chiral $\mathrm{p}_{\mathrm{x}+\mathrm{y}}$-wave pairing in $\mathrm{Sr}_{2} \mathrm{RuO}_{4}$, Phys. Rev. Lett, 92 (24) (2004) 247006-1-247006-4.

[9] T. Hanaguri, S. Niitaka, K. Kuroki, H. Takagi, Uncoventional s-wave superconductivity in $\mathrm{Fe}(\mathrm{Se}, \mathrm{Te})$. Science 328 (2010) 474-476.

[10] M.P. Allan, A.W. Rost, A.P. Mackenzie, Y. Xie, J.C. Davis, K. Klhou, et al., Anisotropic energy gaps of Iron-based superconductivity from intraband quasiprticle interference in LiFeAs, Science 336 (2012) 563-567.

[11] A.F. Hebard, Superconductivity in doped fullerenes, Phys. Today 9 (1992) 26-32.

[12] C.P. Moca, B. Janko/ Theory of strong electron-phonon superconductivity for $\mathrm{MgB}_{2}$ in the framework of two-band model, Physica C 387 (2003) 122-130.

[13] Y. Chen, X.M. Huang, J.W. Wang, Origination of the $T_{c}$ superconductivity of copper oxides from electrons media phonons, Journal of Materials Science and Engineering 4 (2) (2010) 67-75.

[14] X.M. Huang, Y. Chen, The Characteristics of the Superconductivity Mechanism, Journal of Shaanxi University of Technology (Natural Science Edition) 28 (3) (2012) 60-63.

[15] X.M. Huang, Y. Chen, Characteristic on lower carriers dencity in high $\mathrm{T}_{\mathrm{c}}$ copper oxide superconductors, Journal of Shaanxi University of Technology (Natural Science Edition) 30 (1) (2014) 71-74. 